\title{
HOW DO STRENGTHS AND WEAKNESSES IN CORPORATE SOCIAL PERFORMANCE ACROSS STAKEHOLDER DOMAINS AFFECT COMPANY PERFORMANCE
}

\author{
Kamalesh Kumar (University of Michigan - Dearborn) \\ Giacomo Boesso (University of Padova) \\ Giovanna Michelon (University of Exeter)
}

\begin{abstract}
The existing research on corporate social responsibility (CSR) has largely focused on the positive aspect of corporate social performance (CSP) and company performance (CP) and ignored the relationship between actions that would qualify as negative CSP (or weakness in CSP) towards a stakeholder group and company performance. Using data from the KLD collected over a three-year period, this study examines the relationship between both CSP weaknesses and strengths and CP across individual stakeholder domains. Results of the study suggest that strengths in CSP related to primary stakeholder domains is associated with superior company performance. However, this relationship is tenuous, at best, in case of secondary stakeholder domain. As for weaknesses in CSP, the results suggest that if a firm performs poorly in meeting the expectations of one or more stakeholders, it is penalized in the form of poor performance. This finding generally holds true for both primary and secondary stakeholders. Implications of these findings for public policy and businesses planning to address social issues are discussed.
\end{abstract}

KEYWORDS: Stakeholder, Social Performance, Corporate Social Responsibility 


\section{INTRODUCTION}

During the past three decades empirical research on corporate social responsibility (CSR) in general and on stakeholder management in particular has sought an answer to the question: does attending to the needs of the organizations stakeholders, beyond just shareholders, contribute to the company's ability to gain and sustain a performance advantage? Although the existing research on the topic has revealed valuable insights into the Corporate Social Performance (CSP) and Corporate Performance (CP) relationship, most of the studies have examined the CSP-CP relationship in terms of a firm's overall CSP across each of the stakeholder groups by combining strengths and weaknesses in each area and then correlating them to CP (e.g., Choi and Wang, 2009; Hillman and Keim, 2001; Waddock and Graves, 1997), leading to results that are contradictory and equivocal (For reviews see Laplume, Sonpar, and Litz, 2008; Margolis and Walsh, 2001; Orlitzky, Schmidt, and Reynes, 2003.)

The finding that a firm's superior CSP is positively associated with CP does not necessarily suggest that, when firms treat a stakeholder group poorly, they are also likely to have negative or adverse performance outcomes. It seems logical to ask, if CSP is positively related to $\mathrm{CP}$ and the relationship is such that a high level of CSP strengths in a stakeholder domain leads to improved CP, how does this relationship extend to poor or even negative CSP in a stakeholder domain? Is a firm's CP adversely affected if it performs poorly or even fails in meeting the expectations of one or more of its stakeholder groups? Finding an answer to this question is important because, if market forces do not penalize firms that have weak CSP with respect to one or more stakeholder groups, then firms can afford not to act in a socially responsible manner toward these groups.

In a 2006 study Mattingly and Berman conducted an exploratory factor analysis on the Kinder, Lyndenberg, Domini Analytics, Inc. Social Ratings (KLD) database, which has been 
used extensively in scholarly research to operationalize companies' CSP (Coombs and Gilley, 2005; Waddock, 2003) and found that positive CSP and negative CSP are empirically and conceptually distinct constructs. Based on their findings, they concluded that the effects of positive CSP and negative CSP across stakeholder domains should be examined separately when investigating the CSP-CP relationship. Their suggestion was more recently echoed by Choi and Wang (2009), who examined the effect of CSP on the persistence of superior financial performance of firms. While acknowledging that the assessment of CSP with a measure that combines positive CSP and negative CSP was a weakness in their study; they concluded with the suggestion that "future research might explore further ... by examining the separate effects of strengths and weaknesses, both conceptually and empirically" (p. 904). It has been noted that combining a company's strengths and weaknesses in CSP can hide some of the countervailing effects of each of the variables on CP. It is possible that the countervailing effects of positive CSP and negative CSP, when combined in an aggregate, composite measure, may have a masking effect on the CSP and CP relationship (Mishra and Modi, 2012).

The present study attempts to fill this gap in the research on the CSP-CP relationship by creating a framework that separately examines the relationship between CSP strengths and weaknesses and CP across individual stakeholder domains. We think that such a fine-grained approach to studying the CSP-CP relationship will not only contribute to a richer understanding of the relationship but will also help clarify some of the inconsistent findings in past studies.

\section{EXTANT CLASSIFICATION OF CSP: A LITERATURE REVIEW}

The earliest effort to classify CSP came from the seminal work of Carroll (1979) who defined CSP as “a business organization's configuration of principles of social responsibility, processes of social responsiveness, and policies, programs and observable outcomes as they relate to the firm's societal relationship" (Wood, 1991, p. 693). CSP is by definition a 
multidimensional construct that incorporates the policies and procedures firms design to address issues related to stakeholder groups (Wartick and Cochran, 1985).

In the years that followed, a number of scholars proposed integrating CSP with stakeholder management, arguing that doing so would help to clarify the relationship between business and society (Brenner and Cochran, 1991; Clarkson, 1995; Donaldson and Preston, 1995; Jones, 1995; Rowley, 1997). For example, Clarkson (1995) viewed the organization as a set of interdependent relationships and classified stakeholders as primary or secondary. Primary stakeholders are those without whose cooperation and support the firm cannot surviveshareholders, employees, customers, the community, and so on. Clarkson asserted that "the survival and continuing profitability of the corporation depends upon its ability to ... ensure that each primary stakeholder group continues as part of corporation's stakeholder system" (1995, p. 107). By developing longer-term relationships with their primary stakeholders, firms can expand the set of value-creating exchanges with these groups beyond what would be possible otherwise (Hillman and Keim, 2001). Secondary stakeholders (also referred to as public stakeholders) include the environment and societal expectations, such as those related to diversity and human rights issues. These stakeholders lack the direct ties to the firm that characterize the relationships between the firm and its primary stakeholders.

\section{Stakeholder Management, CSP and CP}

Scholars who seek to determine whether attending to the needs of the organization's various stakeholders, beyond just shareholders, contributes to the firm's ability to gain and sustain a performance advantage have proposed various arguments about how CSP may influence a firm's performance (Clarkson, 1995; Wood, 1991). The most common view is that a high level of CSP helps build good relationships that are based on mutual trust and cooperation 
with the stakeholders, which enhance CP. Such a view of the CSP-CP relationship finds support in a number of theories related to CSR and stakeholder management.

According to the stakeholder-agency theory, managers can be seen as the agents of all stakeholders. However, stakeholders differ with respect to the importance of their stakes in the firm and their power vis-a vis the managers (Greenley, Hooley, Broderik, and Rudd, 2004). Hills and Jones (1992) argued that there is "no reason to assume that stakeholder-agent relationships are in equilibrium at any particular time" (p. 132). In fact, there is often considerable friction in the stakeholder-agent relationship because of "some stakeholders' ability to retard equilibrating adjustments that are unfavourable to them" (Donaldson and Preston, 1995, p. 78). Even so, stakeholders are drawn into relationships with a firm to accomplish mutually important goals as efficiently as possible. While agreeing that the goal of shareholder wealth maximization cannot be met by treating stakeholders poorly, Jensen (2002) suggested that firms should improve stakeholder welfare until the marginal cost of doing so, exceeds marginal benefits to shareholders. Empirical studies also support the view that, although high CSP may result in superior CP, firms that spend resources on CSP in excess of its marginal benefits may see a decline in CP. For example, Hillman and Keim (2001) found that, while building better relationships with primary stakeholders could create shareholder value, using corporate resources for general social issues was negatively associated with shareholder value.

The resource dependence theory (Pfeffer and Salancik, 1978) also suggests that different stakeholder groups will attract different levels of attention from a firm. Because of resource dependencies, managers must make strategic decisions within their resource constraints, in ways that improve CP. One of the fundamental tenets of resource dependence theory is that firms will be concerned with, pay attention to, and deal with stakeholder groups that control resources that are critical to $\mathrm{CP}$. In the context of CSP, firms will pay more attention to and be more concerned 
with the issues of stakeholder groups that have resources critical to $\mathrm{CP}$ than they will stakeholder groups who do not control such resources.

Based on the discussion above, it seems reasonable to expect that firms may not be consistent in crafting their social initiatives across stakeholder domains. In fact, differential treatment may even be desirable if the firm needs strategic flexibility. After conducting a detailed analysis of the effect of CSP on CP in terms of each stakeholder groups, Choi and Wang (2009) found that, while the employee and customer aspects of CSP are most critical in maintaining high levels of CP, diversity and customer dimensions of CSP are particularly helpful in improving CP. Choi and Wang concluded by observing that "it might be necessary for firms to strategically prioritize their attention to different stakeholder groups in order to benefit the most from their stakeholder management practices.

\section{DEVELOPMENT OF HYPOTHESES}

We formulate our hypotheses based on the premise that a firm's level of social commitment to stakeholder groups will vary and that differences in a firm's commitment to stakeholder groups will manifest in the form of strength in some areas of CSP and weakness in

others. When firms have limited resources to devote to CSR initiatives, those responsible for corporate governance (the top executives and the board of directors) must determine which stakeholder groups to consider, in what order, and to what extent (Azlan, Shiau and Susela, 2014). Firms, in particular, will be motivated differently in their interactions with primary stakeholders vs. secondary stakeholders. Since the level of a firm's CSP with each of these groups is a matter of policy and choices that are usually made on the basis of outcomes critical to CP.

\section{CSP Strengths in Primary Stakeholder Domains and CP}


Primary stakeholders like customers, employees, community, and governance receive often priority from firms because firms are involved in regular resource exchanges with them (Searcy, McCartney and Karapetrovic, 2008). A firm's interactions with primary stakeholders have been characterized as "relational" (Hillman and Keim, 2001), that involves trust and cooperation developed over time. Researchers have often described the CSR initiatives that are targeted at primary stakeholders as "investments" comparable to those made in R\&D or employee training because they support growth in the same way (Fombrun, Gardner, and Barnett, 2000; Wolf, 2013). Following the resource-based view, one can say that effective management of primary stakeholders — customers, community, employees, and governance - is an intangible, socially complex resource that can enhance a firm's ability to outperform competitors in terms of value creation (Choi and Wang, 2009; Epstein and Widen, 2011).

Strengths in CSP with respect to primary stakeholders can benefit the company both directly and indirectly in ways that are critical to the firm's success. For example, good reputation increases the firm's brand value, which increases the company goodwill that is often reflected in improved market value of the firm (Bhattacharya and Sen, 2004). Reputation has a particularly enduring effect because competitors cannot imitate it (Alniacick, Alniacick, and Genc, 2011). Consideration of externalities that include social issues also helps to attract and retain customers. The increasing desire of customers to purchase products from companies that they deem to be socially responsible is particularly important, given the rising discretionary purchasing power of customers (Clement, 2005). Social initiatives that target customers can also give a firm advantage in terms of its ability to identify trends and changes in the market, allowing the firm to act quickly to establish itself at the forefront of the change (Falck and Heblich, 2007). 
Similarly, strengths in dealing with community, besides helping secure more favorable terms for doing business (Fombrun, 1996), can help a firm build competencies proactively by improving its scanning skills, processes, and systems that increase the organizational preparedness for change, turbulence, and crises (Welford, Chan, and Man, 2007). Strong CSP with respect to employees helps attract, retain, and motivate quality employees who will work hard to enhance the firm's effectiveness. Recent corporate failures and scandals have raised public awareness about governance of companies. Given the rise of social activism and the emergence of new expectations concerning corporate conduct, firms are extending the scope of their governance approaches to CSR in order to improve relationships with shareholders and other key stakeholders. Therefore, it is reasonable to expect that strengths in the primary stakeholder domains of customer, employee, governance and community are positively associated with CP. Accordingly, we hypothesize:

H1(a) Strengths in the employee domain of CSP are positively associated with CP.

H1(b) Strengths in the customer domain of CSP are positively associated with CP.

H1(c) Strengths in the community domain of CSP are positively associated with CP.

H1(d) Strengths in the governance domain of CSP are positively associated with CP.

\section{CSP Strengths in Secondary Stakeholder Domains and CP}

If strengths in the domains that relate to primary stakeholders have a positive association with $\mathrm{CP}$, does this relationship extend to strengths in the domains related to secondary stakeholders? Secondary stakeholders are those who influence or are influenced by the firm but are not engaged in a resource exchange with the firm and are not essential for the firm's survival. CSP related to environment, diversity, and other societal expectations, such as human rights, includes those aspects of stakeholder interactions for which the firm's CSP is in response to normative expectations. A firm's interactions with these stakeholders are characterized as 
"transactional" (Hillman and Keim, 2001), that is, they do not provide a sustained basis for value creation that improves competitive advantage.

Although many of the demands for corporate social initiatives from secondary stakeholders (beyond mandatory legal requirements) are difficult to ascertain and evaluate because of their nebulous and at times ephemeral character (Carroll, 1979); firms are expected to "do something" about these issues. The increasing capacity of non-governmental organizations (NGOs) and activist groups, together with growing awareness in local communities, are two important aspects of the pressure from secondary stakeholder groups that often force firms to mobilize their resources to improve their CSP with stakeholders in this domain.

This raises the question: if and when firms do expand their social initiatives beyond those associated with their primary stakeholders, what effect do these initiatives have on their CP? While investing in relationships with secondary stakeholders may be desirable from a normative view point, these groups do not play a direct role in the firm's value creation process. In addition, strengths in areas like the environment, diversity, and human rights may at times be simply the result of regulatory compliance (Waddock, 2003).

One can argue that firms may incur indirect benefits from an improved CSP in relationship with these groups. For example, respect for and good management of diversity can help firms attract and retain quality employees. Similarly, environment-friendly practices and respect for human rights can create a positive impression among customers and the public at large (Brammer, Hoejmose and Marchant, 2012; Stanny, 2013). Even so, the nature of the firm's relationship with secondary stakeholder groups is such that the relationship does not provide a basis for value creation that leads to improved competitive advantage since other firms can easily make the same choice to participate in a social issue of important to a secondary stakeholder group. To the extent that performance advantages from many social initiatives related to the 
secondary stakeholder groups can easily be duplicated by other firms; they cannot provide the basis for competitive advantage (Choi and Wang, 2009; Hillman and Keim, 2001). Therefore, the CSP-CP relationship in these stakeholder domains is unlikely to be the same as that in the primary stakeholder domain. Therefore, it is reasonable to hypothesize:

H2(a) Strength in the environmental domain of CSP is not associated with CP.

H2(b) Strength in the diversity domain of CSP is not associated with CP.

H2(c) Strength in the human rights domain of CSP is not associated with CP.

\section{CSP Weaknesses in Primary Stakeholder Domains and CP}

It is logical to ask, if CSP in the primary stakeholder domains is positively related to $\mathrm{CP}$, and the relationship is such that high CSP strengths improves CP, how this relationship extends to poor or even negative CSP in these stakeholder domains. Is a firm's CP adversely affected if it performs poorly or even fails to meet the expectations of one or more of the primary stakeholder groups, or are firms only rewarded for CSP strengths in primary stakeholder domains but suffer no negative performance consequences for poor or negative CSP?

Because firms are involved in resource exchanges with primary stakeholders, it is likely that weakness in terms of CSP with these groups may put them at a competitive disadvantage. Ignoring the stakeholders in this group may result in cost savings but could also risk company goodwill and reputation in the long run. In addition, if any stakeholder group, such as customers or employees, becomes so dissatisfied as to withdraw from the firm's system in whole or in part, the firm is likely to incur serious damage (Clarkson, 1995). Customers may boycott the products of a firm with negative CSP, or it may suffer from low employee commitment and high turnover, all of which adversely affect CP. A firm that does little or nothing to build trust with the community or create loyalty with customers or employees may see a competitive disadvantage. Similarly, weak corporate governance, besides limiting the company's ability to utilize its 
resources effectively, can also create serious reputational issues (Falck and Heblich, 2007). Therefore, we argue:

H3(a) Weakness in the employee domain of CSP is negatively associated with CP.

H3(b) Weakness in the customer domain of CSP is negatively associated with CP.

H3(c) Weakness in the community domain of CSP is negatively associated with CP.

H3(d) Weakness in the governance domain of CSP are negatively associated with CP.

\section{CSP Weaknesses in Primary Stakeholder Domains and CP}

As for secondary stakeholder groups, although firms are not dependent on them for their survival, ignoring their interests can also cause a firm damage (Clarkson, 1995). Secondary stakeholders who are opposed to or unhappy with a firm's policies or programs or who feel that a firm has not fulfilled its responsibilities toward them can mobilize public opinion, requiring companies to act in their interest (Clement, 2005). Moreover, if a firm's weakness in a secondary stakeholder domain is the result of the "ecological selection process" (Husted, 2000) — that is, if it is based upon evaluation of the salience of the issues critical to business operation and the competitive context of the firm - then one would not expect to see much of an association between weaknesses in the secondary stakeholder domain and CP. Finally, since weaknesses are

not simply the converse of strengths but are qualitatively distinct types of corporate social actions, we may find unique but not necessarily inverse association with CP (Mattingly and Berman, 2006). Based on this discussion, we argue:

H4(a) Weakness in the environmental domain of CSP is associated with CP.

H4(b) Weakness in the diversity domain of CSP is associated with CP.

H4(c) Weakness in the human rights domain of CSP is associated with CP.

\section{RESEARCH METHOD}




\section{Sample and data collection}

Data on CSP were drawn from the Kinder, Lyndenberg, Domini Analytics, Inc. (KLD) Social Ratings database. KLD uses a proprietary rating system to rate the social, environmental, and governance performance of companies on more than 280 data points. The database includes all firms on Standard and Poor's 500 and approximately 150 firms included in the Domini Social Index (DSI) 400. Based on these ratings, KLD publishes the annual list of 100 Best Corporate Citizens. For this study we used the KLD ratings of the 100 Best Corporate Citizens over a three year period because we were specifically interested in companies' longer-term strategic approach to CSR and the effect of their CSP on CP. KLD data is considered "the most comprehensive and prominent data" on stakeholder management (Coombs and Gilley, 2005, p. 830), and have been referred to as "the de facto standard at the moment" for measuring stakeholder management (Waddock, 2003, p. 369). Since not all companies made the 100 Best Corporate Citizens list in all three years, the selection process yielded a final sample of 188 companies and 3,948 CSP ratings in seven areas of CSP over a three-year period. We chose the sample for this study from the 100 Best Corporate Citizens pool because these companies are known for actively managing their CSR initiatives, so they can be expected to exhibit the kind of strengths and weaknesses in various areas of CSP that are meaningful and relevant to the CSP-CP relationship investigated in this study. Data on CP and control variables were collected from Thomson's DataStream, one of the largest databases of financial performance and other company-related statistics.

\section{Measures}

Dependent variables: The primary dependent variable in this study was $\mathrm{CP}$, which was measured both in terms of accounting-based measures and market-based measures. For accounting-based measures we chose EBITDA, capital expenditure, and intangibles. Compared to many other accounting-based measures, EBITDA is less subject to managers' discretionary 
policy choices regarding surplus resources, so it is a better reflection of a company's actual financial performance (Orlitzky et al., 2003). Capital expenditures are suggestive of the longterm initiatives that companies are pursuing to improve their future performance, and intangibles capture gains that may not be directly reflected in the accounting-based measure but have the potential to improve a company's future performance. For the market-based measure we selected companies' market value at the end of each fiscal year. A company's market value over time, one could argue, reflects both the tangible and intangible gains that may have resulted — and even those likely to result-from sound CSR initiatives over time (Choi and Wang, 2009; Coombs and Gilley, 2005).

Control variables: Because the dependent variables used in the study capture the firms' financial and market-based performance, we control for factors that could systematically affect such performance. Therefore, we included size and industry as control variables based on the recommendations and findings of previous researchers (Choi and Wang, 2009; Coombs and Gilley, 2005; Frias, Rodriguez and Garcia, 2014).

Independent variables: The independent variables used in this study are the seven areas of stakeholder management on which KLD rates CSP: environment, community, corporate governance, diversity, employee relations, product quality and safety, and human rights. KLD ratings indicate the presence or absence of strengths and weaknesses in each of the seven areas of CSR. The rating scores are based on an integer scale, where -2 indicates major concerns, -1 indicates concerns, 0 is neutral, +1 indicates strength, and +2 indicates major strength. Thus, a low rating in an area indicates weakness or the absence of strength, while a high rating indicates the presence of positive activity or the absence of weakness. Using KLD ratings, we constructed two indices for each of the seven stakeholder domains. We measure CSR weaknesses as equal to the KLD score if below the yearly median, 0 otherwise and CSR strengths $=$ KLD score if above 
the median, 0 otherwise. Our measurement approach is much more in-depth than those of previous studies since most of those studies either developed an aggregate measure of CSP (e.g., Hillman and Kein, 2001) or examined overall CSP across each of the stakeholder domains by combining strengths and weaknesses (e.g., Choi and Wang, 2009). Moreover, it directly benchmarks the performance to of each company to that of the top peers. Appendix provides a sample of the KLD items we used to evaluate strengths and weaknesses in each of the seven stakeholder domains.

\section{Models}

In selecting the appropriate multivariate statistical method for data analysis, we recognized that the data set for this study is panel data, because many companies made the best corporate citizens list more than once during the three-year period, and CSP ratings may have varied during this period. Panel data have the between-subjects information among subjects for any given time period, and they have the within-subjects information for the same subjects across time (Wooldridge, 2002). We performed a panel-corrected standard error linear model, assuming within-unit homoskedasticity because we found different error variances for the different cross-sections, and with such cross-section heteroskedasticity the OLS standard errors are inconsistent. Moreover, because we included in our research models time-invariant variables (industry effects), panel data modeling with fixed effects was deemed inappropriate for analysis.

In order to test our hypotheses, we first tested the relationship between CSP and CP for strengths and weaknesses in each of the seven stakeholder areas. For each measure of CP, we ran seven separate regression models, one for each of the seven stakeholder groups:

Corporate Performance $=\beta_{0}+\beta_{1}$ KLD Weakness $_{i t}+\beta_{2}$ KLD Strengths St $_{i t}+\beta_{3}$ size $_{i t}+$ (1) $\sum_{\text {ind }=1}^{8} \beta_{4 i n d}$ Industry ind $_{\text {in }}$ 
Next, we ran the full model for each measure of $\mathrm{CP}$ by considering the joint effect of strengths and weaknesses in each of the seven areas of CSP:

Corporate Performance $=\beta_{0}+\beta_{1}$ Employee Weakness $_{i t}+\beta_{2}$ Employee Strengths $_{i t}+$ $\beta_{3}$ Customer Weakness $_{i t}+\beta_{4}$ Customer Strengths $_{i t}+\beta_{5}$ Community Weakness $_{i t}+$ $\beta_{6}$ Community Strengths $_{i t}+\beta_{7}$ Governance Weakness $_{i t}+\beta_{8}$ Governance Strengths $_{i t}+$ $\beta_{9}$ Environment Weakness $_{i t}+\beta_{10}$ Environment Strengths $_{i t}+\beta_{11}$ Diversity Weakness ${ }_{i t}+$ $\beta_{12}$ Diversity Strengths $s_{i t}+\beta_{13}$ Human rights Weakness $_{i t}+$

(2) $\beta_{14}$ Human rights Strengths $s_{i t}+\beta_{15}$ size $_{i t}+\sum_{\text {ind }=1}^{8} \beta_{16 i n d}$ Industry $_{\text {ind }}$

\section{RESULTS}

Table 1 provides descriptive statistics (panel A) and correlations (panel B) for all variables included in the study. The mean CSP score related to strengths across the seven stakeholder domains shows a good deal of variation, from a low of .38 for strengths in human rights to a high of 1.12 in the area of community strength. Similarly, weaknesses related to CSP is highest in the areas of governance and human rights (-.20 each) and lowest in the employee domain (.002). The standard deviations in CSP in terms of strengths and weaknesses across the seven stakeholder domains are substantial, indicating major differences among firms. The correlations between independent variables are moderate but meaningful, and the relationship between CSP and CP in general is stronger and more frequently present with accounting-based measures than with market-based measure.

Insert Table 1 about here

Table 2 provides results for the regression analyses relative to the associations between $\mathrm{CP}$ and strengths and weaknesses in each of the seven domains of CSP. All of the models are significant, although the relationship is generally stronger in terms of accounting-based measures than market-based measures. Hypotheses 1(a)-(d) proposed positive relationships between 
strengths in primary stakeholder domains and $\mathrm{CP}$, and results provide support for the employee (1a), community (1c), and governance (1d) domains. However no support was found for the customer 1(b) domain.

As for the secondary stakeholder domain, regression results for strength in the environment domain are unrelated to CP, providing support for hypothesis 2 (a). However, contrary to the predictions made by hypotheses 2(b) and 2(c), strengths in the diversity and human rights domains are positively associated with measures of $\mathrm{CP}$.

Hypotheses 3(a)-(d) were related to weaknesses in the primary stakeholder domains. Results of regressions did not support hypothesis 3(a) for the employee domain but did support 3(b) (customer), 3(c) (community), and 3(d) (governance) domains.

Results for hypotheses related to weakness in the secondary stakeholder domain show that weaknesses in the environment domain 4(a) were not associated with $\mathrm{CP}$, thus failing to provide support for that hypothesis. However, results support hypotheses 4(b) (diversity) and 4(c) (human rights) domains. Further discussion and possible explanations for the findings that did not support the hypothesized relationships are provided in the discussion section.

\section{Insert Table 2 about here}

Next, we subjected our findings to stricter tests by creating comprehensive models that simultaneously consider the strengths and weaknesses in each of the seven domains of CSP. The level of a firm's CSP with various stakeholder groups are policy decisions made on the bases of achieving outcomes that its managers deem critical to CP. Therefore, these decisions involve simultaneous evaluation of the demands of the stakeholder groups and their salience to the performance of the firm (Mitchell, Agle, and Wood, 1997). It seems logical; therefore, that one 
examines the firm's CSP with respect to all of its stakeholder groups together. Results of multivariate regression, in which strengths and weaknesses across the seven stakeholder domains are simultaneously tested in a comprehensive model, are presented in Table 3. With a few exceptions, these results are similar to those described in Table 2. Weaknesses in the customer and community domains, which were significantly associated with $\mathrm{CP}$ when examined individually, are now unrelated to $\mathrm{CP}$, as is strength in the community domain.

Insert Table 3 about here

\section{Robustness checks}

We subjected our results to retest using robustness and sensitivity tests. First, we ran all regression models using both robust (clustered) variance estimates, which provided similar results. We also performed a Durbin-Wu-Hausman test for simultaneity in the relationship between CP and CSP and found no evidence of simultaneity. Therefore, the estimates provided by the panel-corrected standard error model are consistent. We also performed the Wooldridge test for autocorrelation in panel data and found no serial correlation in the error terms of our models. Next, we tested the sensitivity of our results to the measures employed in our study with results similar to those noted in our multivariate regression analyses when size is measured as the natural logarithm of sales instead of number of employees and when all dependent variables are scaled by either number of employees or total sales or total assets.

\section{DISCUSSION}

With regard to primary stakeholder groups, the results of this study generally confirm hypotheses that strengths in CSP are positively related to CP, while weaknesses are negatively related to $\mathrm{CP}$. For secondary stakeholder groups, results show that strengths in these domains 
have mixed association with $\mathrm{CP}$, while weaknesses are associated with, but not necessarily in a way that is inverse to strengths.

Since the results are somewhat mixed they require discussion and explanation. Strengths in the employees, the community, and governance, all of which are in the primary stakeholder domain, are positively related to CP. However, the same relationship was not observed for customers, who are also primary stakeholders. To explain this finding we first turn to the stakeholder agency theory (Donaldson and Preston, 1995; Hills and Jones, 1992), which suggests that firms should improve stakeholder welfare until the marginal cost of doing so exceeds marginal benefits. However, if firms expend resources of any kind in a stakeholder domain in excess of marginal benefits, they experience a corresponding decline in CP. Since the sample for this study consists of 100 best corporate citizens, it is possible that these companies are making such extraordinary investments in building good relationship with customers that they are seeing declining benefits to CP. This explanation appears even more credible when one takes a closer look at the customer-related issues monitored by KLD. KLD's rating of the customer dimension centers on product quality, research and development, innovation, and benefits to the economically disadvantaged. Engaging in CSR in these areas entails substantial expense without much return in the short run.

Regarding the relationship between strengths in the secondary stakeholder domains and $\mathrm{CP}$, strengths with regard to the diversity and human rights groups had significant positive association with $\mathrm{CP}$, contrary to our expectations. This finding, is also contrary to the findings of Hillman and Keim (2001), who found that participation in broader social issues that are not directly related a firm's activities “may adversely affect a firm's ability to create shareholder wealth" (p. 135). As regards the results related to diversity, KLD's rating considers such issues as family benefits and the firm's treatment of female, minority, disabled, and gay and lesbian 
employees, so responding to these issues means that the firm is inclusive in its employment practices. Diversity-related stakeholders are not only those who have normative expectations from a firm; they are also involved in direct resource exchanges as employees who participate in the firm's activities and have expectations for the firm's treatment of non-employed diversityrelated stakeholders (Mattingly and Berman, 2006). It would, therefore, be prudent to treat this finding as equivocal.

The positive relationship between strengths in the human rights domain and $\mathrm{CP}$ can, perhaps, be best explained using the relationship between company reputation and performance (Ditlev-Simonson and Midttun, 2011). It is commonly accepted that mutual trust and cooperation in terms of engaging or not engaging in certain activities that are of concern to various stakeholder groups generally enhances a firm's reputation; although not necessarily in the short run (Szwajkowski and Figlewicz, 1999). Drawing upon the stakeholder influence capacity (SIC) theory (Barnett, 2007), one could argue that the 100 best corporate citizens that constitute the sample for this study, includes companies that have adequately accrued stakeholder influence capacity in the human rights domain, enabling them to benefit from it in form of improved CP. As such, once again, the result can best be characterized as tenuous, requiring further investigation.

We next turn to the findings related to the relationships between weaknesses in stakeholder domains and CP. The results of this study support the assertion that weaknesses in the primary stakeholder domains, in general, are negatively associated with CP. With the exception of weaknesses in the employee domain, which is uncorrelated with CP, weaknesses in the customer, community, and governance domains are negatively associated with $\mathrm{CP}$. An explanation for the unexpected result in the employee domain may be found in the weakness rating for the sample of this study. The results presented in Table 1 show that the sample's mean 
for employee weaknesses is close to zero, which the KLD rating scale interprets as "neutral." This interpretation suggests that the sample firms had little or no weakness related to their social performance in the employee domain, making the data inappropriate for the relationship under investigation.

As for weaknesses related to the secondary stakeholder domain and CP, the hypotheses predicted that their relationship with $\mathrm{CP}$ is distinct, but not necessarily inverse, from the relationships noted for strengths. The results of this study show that weaknesses in each of the three secondary stakeholder domains - environment, diversity, and human rights — are negatively associated with performance. If firms perform poorly in or fail in meeting the expectations of stakeholders in these groups, they are penalized. This finding adds another dimension to the findings of Hillman and Keim (2001), who concluded that participating in social issues beyond those that affect primary stakeholders may adversely affect a firms' performance. Based on our findings, it appears reasonable to conclude that, when firms do not act in a socially responsible manner toward secondary stakeholders, they risk poor $\mathrm{CP}$.

\section{IMPLICATIONS FOR BUSINESS, PUBLIC POLICY AND CONCLUSIONS}

The rationale for this study was based upon the argument that CSP is a multidimensional construct and that disaggregation of CSP in terms of strengths and weaknesses across individual stakeholder domains is necessary in order to better understand CSP's relationship with CP. Our research suggests that investing in CSP related to primary stakeholder domains results in strengths that complement $\mathrm{CP}$, but we are not certain that this relationship extends to secondary stakeholders as well. As for weaknesses in CSP, one can conclude that, if a firm performs poorly in or fails in meeting the expectations of one or more stakeholder groups, it is penalized in the form of poor performance. This finding generally holds true for both primary and secondary stakeholders. 
Findings of this study have some important implications for public policy, as well as for CSR initiatives being pursued by businesses. From the corporate perspective, while companies are increasingly realizing that stakeholder perceptions can be critical to $\mathrm{CP}$ - and sometimes even survival (Boesso and Kumar, 2007) — CSR initiatives have come under closer scrutiny in terms of the business benefits received from supporting the demands of disparate groups of stakeholders. Failure to supplement CSR initiatives with economic considerations may be why many companies view them as a non-productive cost or as a "tax or license for doing business" (Peloza, 2006).

The finding that, even though social investments made in the secondary stakeholder domains of environment, diversity, and human rights may not pay in the form of improved CP, but companies that ignore CSR initiatives aimed toward these stakeholder groups or perform poorly in meeting the CSR-related expectations of these groups may be penalized in the form of poor $\mathrm{CP}$, provides guidelines to managers in identifying, prioritizing and addressing the myriad of social issues that a company can address. Since this study examined the relationship between CSR and CP across each stakeholder domain, the findings can guide managers in developing better focused and meaningful forms of CSR initiatives that will demonstrably improve CP by increasing corporate goodwill (Ditlev-Simonson and Midttun, 2011).

From the public policy perspective, even as more businesses embrace CSR, evidence from practice continues to show that companies often treat CSR largely as an exercise in public relations, media campaigns, and reputation management (Chatterji, Levine, and Toffel, 2009). Popular press and scholars alike have expressed reservations about the true impact of corporate social initiatives, noting that existing CSR practices and processes, "have little to do with extending accountability and amount to nothing more than exercise in stakeholder management and corporate spin" (Cooper and Owen, 2007, p. 650). Public policy experts have noted that 
companies' social initiatives often look like a "hodgepodge of uncoordinated CSR and philanthropic activities...that neither make any meaningful social impact nor strengthen the company’s performance" (Porter and Kramer, 2006, p. 9).

To the extent that results of this study show that investing in CSR related to stakeholder groups that may not have a direct bearing on $\mathrm{CP}$, may be complementary to $\mathrm{CP}$ goals and may provide a basis for superior performance, it can provide some guidelines for initiating a dialogue with various stakeholder groups to gauge their views and aspirations. Based on the understanding that is likely to emerge from such dialogues, companies can prioritize which stakeholders' demands to address and construct their CSR initiatives in a strategic way by creating propositions that are based upon corporate capabilities that are particularly suitable to creating value for different stakeholder groups.

One of the limitations of this study is associated with the choice of sample and the way in which it operationalized CSP. Using CSP from the KLD database of the one hundred best companies does not capture all of the intricacies involved in managing stakeholder relationships. The generalizability of the findings of the study is also somewhat limited, given that the sample consisted of only the 188 most highly rated companies. It remains uncertain whether these results will hold with a larger cross-section of companies. Future researchers are well advised to examine the CSR-CP relationship over a longer period, considering that CSR initiatives may have a lagged relationship with $\mathrm{CP}$.

These limitations also create additional opportunities for future research. The relationship between CSP and CP is more complex than the data available through KLD allowed us to model, so this study should encourage future research that focuses on CSP strengths and weaknesses across stakeholder domains using a broad-based sample and data collected over a longer period of time. 
So far as the contributions of this study are concerned, notwithstanding its limitations, it provides a somewhat more complete insight into the CSP-CP relationship than has been offered to date. Its findings also help to clarify some of the inconsistent findings about the CSP-CP relationship that have been noted in extant studies, which have led to an intense debate among scholars and managers concerning whether CSP and CP are positively related, negatively related, or unrelated. We do not suggest that our findings put an end to this long-standing debate, but we hope that it has added one more piece to the puzzle. Further research efforts along these lines can enrich the stakeholder management and CSR literature and provide meaningful and practical guidelines for crafting corporate social initiatives. 


\section{REFERENCES}

Alniacik U, Alniacik E, Genc N. 2011. How corporate social responsibility information influences stakeholders' intentions. Corporate Social Responsibility and Environmental Management. 18: 234-245. DOI: 10.1002/csr.245

Azlan A, Shiau PL, Susela Devi S. 2014. The Influence of Governance Structure and Strategic Corporate Social Responsibility Toward Sustainability Reporting Quality. Business Strategy and the Environment 23: 217-235. DOI: 10.1002/bse.1767

Barnett ML. 2007. Stakeholder influence capacity and the variability of financial returns to corporate social responsibility. Academy of Management Review. 32: 794-816. DOI: 10.5465/AMR.2007.25275520

Brammer S, Hoejmose S, Marchant K. 2012. Environmental management in the SMEs in the UK: practices, pressures and perceived benefits. Business Strategy and the Environment 21: 423-434. DOI: 10.1002/bse.717

Boesso G, Kumar K. 2007. Drivers of corporate voluntary disclosure: A framework and empirical evidence from Italy and the United States. Accounting, Auditing and Accountability Journal 20: 269-296. DOI: 10.1108/09513570710741028

Bhattacharya CB, Sen S. 2004. Doing better at doing good: When, why and how consumers respond to corporate social initiatives. California Management Review. 47: 9-24. DOI: $10.2307 / 41166284$

Brenner SN, Cochran P. 1991. A stakeholder theory of the firm: Implications for business and society theory and research. Proceedings of the International Society for Business and Society, 449-467.

Carroll AB. 1979. A Three-Dimensional Conceptual Model of Corporate Performance. The Academy of Management Review. 4: 497-505. DOI: 10.5465/AMR.1979.4498296 
Chatterji A, Levine D., Toffel, M.W. 2009. How Well Do Social Ratings Actually Measure Corporate Social Responsibility? Journal of Economics and Management Strategy. 18: 125-169. DOI: 10.1111/J.1530-9134.2009.00210

Choi J, Wang H. 2009. Stakeholder relations and the persistence of corporate financial performance. Strategic Management Journal. 30: 895-907. DOI:10.1002/smj.759

Clarkson MBE. 1995. A stakeholder framework for analyzing and evaluating corporate social performance. Academy of Management Review. 20: 92-117. DOI:10.2307/258888

Clement RW. 2005. The lessons from stakeholder theory for U.S. business leaders. Business Horizons. 48: 255-264. DOI: 10.1016/j.bbr.2011.03.031

Coombs JE, Gilley KM. 2005. Stakeholder management as a predictor of CEO compensation: Main effects and interactions with financial performance. Strategic Management Journal 26: $827-840$. DOI: $10.1002 / \mathrm{smj} .476$

Cooper SM, Owen DL. 2007. Corporate Social Reporting and Stakeholder Accountability: The Missing Link. Accounting, Organizations and Society. 32: 649-667. DOI: 10.1016/j.aos.2007.02.001

Ditlev-Simonsen CD, Midttun D. 2011. What motivates managers to pursue corporate responsibility? A survey among key stakeholders. Corporate Social Responsibility and Environmental Management 18: 25-38. DOI: $10.1002 / \mathrm{csr} .237$

Donaldson T, Preston LE. 1995. The stakeholder theory of the corporation: concepts, evidence and implications. Academy of Management Review. 20: 65-91. DOI: 10.5465/AMR.1995.9503271992

Epstein, MJ, Widen, SK. 2011. Facilitating sustainable development decisions: measuring stakeholders reactions. Business Strategy and the Environment 20: 107-123. DOI: $10.1002 /$ bse. 680 
Falck O, Heblich S. 2007. Corporate social responsibility: Doing well by doing good. Business Horizons. 50: 247-254. DOI:10.1016/j.bushor.2006.12.002

Fombrun CJ. 1996. Reputation: Realizing value from the corporate image. Harvard Business School Press: Boston, MA.

Fombrun CJ, Gardberg N, Barnett M. 2000. Opportunity platforms and safety nets: Corporate citizenship and reputational risk. Business and Society Review 105: 85-106. DOI:10.1111/0045-3609.00066

Frias-Aceituno JV, Rodriguez-Ariza L, Garcia-Sanchez IM. 2014. Explanatory Factors of Integrated Sustainability and Financial Reporting. Business Strategy and the Environment 23: 56-72. DOI: $10.1002 / b s e .1765$

Greenley, GE, Hooley GJ, Broderik HA, Rudd J. 2004. Strategic Planning Differences among Different Multiple Stakeholder Orientation Profiles. Journal of Strategic Marketing. 12: 163-182. DOI: $10.1080 / 0965254042000262887$

Hillman AJ, Keim GD. 2001. Stakeholder value, stakeholder management, and social issues: What's the bottom line? Strategic Management Journal 22: 125-139. DOI:10.1002/10970266(200101)22:2<125::AID-SMJ150>3.0.CO;2-H

Hills CWL, Jones TM. 1992. Stakeholder-Agency Theory. Journal of Management Studies. 29: 131-154. DOI: 10.1111/j.1467-6486.1992.tb00657.x

Husted BW. 2000. A contingency theory of corporate social performance. Business and Society. 39: 24-48. DOI: 10.1177/000765030003900104

Jensen MC. 2002. Value maximization, stakeholder theory, and the corporate objective function. Business Ethics Quarterly. 12: 235-256. DOI:10.2307/3857812

Jones T. 1995. Instrumental stakeholder theory: a synthesis of ethics and economics. Academy of Management Review. 20: 404-437. DOI:10.2307/258852 
Laplume AOK, Sonpar K, Litz RA. 2008. Stakeholder theory: Reviewing a theory that moves us. Journal of Management. 34: 1152-1189. DOI: 10.1177/0149206309344118

Margolis JD, Walsh JP. 2001. Social enterprise series n. 19 - Misery loves companies: Whither social initiatives by business?” Harvard Business School Working Paper Series. n. 01-058.

Mattingly JE, Berman SL. 2006. Measurement of corporate social action: Discovering taxonomy in the Kinder Lydenburg Domini Ratings Data. Business and Society 45: 20-46. DOI:10.1177/0007650305281939

Mishra S, Modi SD. 2012. Positive and Negative Corporate Social Responsibility, Financial Leverage, and Idiosyncratic Risk. Journal of Business Ethic. DOI: 10.1007/s10551-0121526-9.

Mitchell RK, Agle BR, Wood DJ. 1997. Toward a theory of stakeholder identification and salience: defining the principle of who and what really counts. Academy of Management Review. 22: 853-86. DOI: 10.1177/1470593109103070

Orlitzky M, Schmidt FL, Rynes SL. 2003. Corporate social and financial performance: A meta analysis. Organizational Studies 24: 403-441. DOI:10.1177/0170840603024003910

Peloza J. 2006. Using Corporate Social Responsibility as Insurance for Financial Performance. California Management Review. 48: 52-72. DOI: 10.2307/41166338

Porter ME, Kramer MR. 2006. Strategy and society: The link between competitive advantage and corporate social responsibility, Harvard Business Review 86: 78-92.

Rowley, T.J. 1997, “Moving beyond Dyadic Ties: A Network Theory of Stakeholder Influences," Academy of Management Review, 22, 887-910. DOI: 10.2307/259248

Searcy C, McCartney D, Karapetrovic S. 2008. Identifying priorities for action in corporate sustainable development indicator programs. Business Strategy and the Environment 17: 137-148. DOI: 10.1002/bse.509 
Stanny E. 2013. Voluntary Disclosures of Emissions by US Firms. Business Strategy and the Environment 22: 145-158. DOI: 10.1002/bse.1732

Szwajkowski, E., and R.E. Figlewicz, 1999, "Evaluating corporate performance: A comparison of the Fortune reputation survey and the Socrates social rating database," Journal of Managerial Issues, 11, 137-154. www.jstor.org/stable/40604261

Waddock S. 2003. Myths and realities of social investing. Organization and Environment 16: 369-380. DOI: 10.1177/1086026603256284

Waddock S, Graves S. 1997. The corporate social performance-financial performance link. Strategic Management Journal 18: 303-319. DOI: $10.1002 /(\mathrm{SICI}) 1097-$ 0266(199704)18:4<303::AID-SMJ869>3.0.CO;2-G

Wartick SL, Cochran PL. 1985. The Evolution of the Corporate Social Performance Model. Academy of Management Review, 10: 758-769. DOI: 10.1177/000765039903800303

Welford R, Chan C, Man M. 2007. Priorities for corporate social responsibility: A survey. Corporate Social Responsibility and Environmental Management. 15: 5-62 DOI: $10.1002 /$ csr. 166

Wood DJ. 1991. Corporate social performance revisited. Academy of Management Review. 16: 691-718. DOI: 10.5465/AMR.1991.4279616

Wooldridge, JM. 2002. Econometric Analysis of Cross Section and Panel Data. MIT Press: Cambridge, MA.

Wolf J. 2013. Improving the Sustainable Development of Firms: The Role of Employees. Business Strategy and the Environment 22: 92-108. DOI: 10.1002/bse.1731 
Table 1.

Descriptive Statistics and Correlation

\section{Panel A. Descriptive Statistics}

\begin{tabular}{lrrrr} 
& \multicolumn{1}{c}{ Mean } & Std. Dev & \multicolumn{1}{c}{ Min } & \multicolumn{1}{c}{ Max } \\
\hline EBITDA & $2,358.41$ & $4,596.45$ & $-1,494.00$ & $43,028.00$ \\
COM_VALUE & $32,716.29$ & $91,765.86$ & 0.00 & $926,269.40$ \\
CAP_EXP & 424.75 & 867.97 & 0.00 & $5,818.00$ \\
INTANGIBLES & $2,547.74$ & $7,380.82$ & 0.00 & $89,026.99$ \\
Employee weakness & 0.00 & 0.35 & -1.46 & 0.60 \\
Employee strengths & 1.01 & 1.04 & 0.00 & 4.66 \\
Costumer weakness & -0.13 & 0.38 & -2.92 & 0.12 \\
Costumer strengths & 0.65 & 0.57 & 0.00 & 2.77 \\
Community weakness & 0.05 & 0.28 & -1.80 & 0.56 \\
Community strengths & 1.12 & 1.43 & -0.24 & 5.99 \\
Governance weakness & -0.20 & 0.50 & -3.52 & 0.35 \\
Governance strengths & 0.73 & 0.78 & 0.00 & 4.00 \\
Environment weakness & 0.03 & 0.19 & -1.22 & 0.54 \\
Environment strengths & 0.90 & 1.12 & 0.00 & 4.75 \\
Diversity weakness & 0.02 & 0.31 & -1.47 & 0.62 \\
Diversity strengths & 1.11 & 1.05 & 0.00 & 4.08 \\
Human rights weakness & -0.20 & 0.62 & -4.29 & 0.00 \\
Human rights strengths & 0.38 & 0.34 & 0.00 & 3.13 \\
Size & 9.21 & 1.70 & 5.06 & 12.96 \\
\hline
\end{tabular}

